\title{
CARACTERIZAÇÃO QUÍMICA DAS ANTOCIANINAS DO FRUTO DE JUÇARA (Euterpe edulis MARTIUS)
}

\author{
Natalia Caroliny da Silva Dias ${ }^{1}$ \\ Kézia Ferreira Marques ${ }^{2}$ \\ Monaly Correa Alves ${ }^{3}$ \\ Jaqueline Rodrigues Cindra de Lima Souza ${ }^{4}$ \\ Tércio da Silva de Souza ${ }^{5}$ \\ Adésio Ferreira $^{6}$
}

Resumo: A antocianina é um pigmento presente no reino vegetal com inúmeras funções indo desde coloração até bioatividade em diversos sistemas. Atualmente, as indústrias de alimentos têm investido em pesquisas e procurado substituir seus aditivos sintéticos por compostos naturais, os quais têm se tornado uma ferramenta atrativa no mercado como corante a alimentos e prevenção do processo oxidativo. Este trabalho teve como objetivo caracterizar as antocianinas presentes no extrato de Juçara das amostras coletadas na região Sul e Caparaó do estado do Espírito Santo. Os resultados encontrados na análise de $\mathrm{pH}$ diferencial do extrato foi $20,94 \pm 1,57 \mu \mathrm{g} / \mathrm{g}$ de Antocianina Monomérica do extrato. O município de Alegre apresentou o maior teor de açúcar total e redutor, respectivamente 6,87 $\pm 1,17$ e 6,12 $\pm 2,37$. As antocianinas existentes no juçara possui capacidade de inserção no mercado, uma vez que os dados comprovam a sua presença expressiva no fruto.

Palavras-chave: Pigmento; Composto; Natural; Identificação; Antioxidante.

\footnotetext{
1 Pós-Graduando em Genética e Melhoramento/ Universidade Federal do Espírito Santo, Centro de Ciências Agrárias. Alegre/ES, Brasil. E-mail: nataliabioifes@hotmail.com.

2 Graduando de Engenharia de Aquicultura/ Instituto Federal de Educação Ciência e Tecnologia do Espírito Santo. Alegre/ES, Brasil. E-mail: keziaffortunato@gmail.com.

3 Graduando de Engenharia de Aquicultura/ Instituto Federal de Educação Ciência e Tecnologia do Espírito Santo. Alegre/ES, Brasil. E-mail: monalycorreaalves@gmail.com.

4 Pós-Graduação em Agroecologia/ Instituto Federal de Educação Ciência e Tecnologia do Espírito Santo. Alegre/ES, Brasil. E-mail: jrsouza@ifes.edu.br.

5 Doutorado em Produção Vegetal/ Universidade Federal do Espírito Santo, Centro de Ciências Agrárias. Alegre/ES, Brasil. E-mail: tssouza@ifes.edu.br.

6 Doutorado em Genética e Melhoramento/ Universidade Federal de Viçosa, Brasil. E-mail: adesioferreira@gmail.com.
} 